\title{
Neuromodulation can reduce aggressive behavior elicited by violent video games
}

\author{
Paolo Riva ${ }^{1}$ - Alessandro Gabbiadini ${ }^{1}$ Leonor J. Romero Lauro ${ }^{1}$. \\ Luca Andrighetto $^{2}$ - Chiara Volpato ${ }^{1}$ - Brad J. Bushman ${ }^{3,4}$
}

Published online: 29 December 2016

(C) Psychonomic Society, Inc. 2016

\begin{abstract}
Research has shown that exposure to violent media increases aggression. However, the neural underpinnings of violent-media-related aggression are poorly understood. Additionally, few experiments have tested hypotheses concerning how to reduce violent-media-related aggression. In this experiment, we focused on a brain area involved in the regulation of aggressive impulses - the right ventrolateral prefrontal cortex (rVLPFC). We tested the hypothesis that brain polarization through anodal transcranial direct current stimulation (tDCS) over rVLPFC reduces aggression related to violent video games. Participants $(N=79)$ were randomly assigned to play a violent or a nonviolent video game while receiving anodal or sham stimulation. Afterward, participants aggressed against an ostensible partner using the Taylor aggression paradigm (Taylor Journal of Personality, 35, 297310, 1967), which measures both unprovoked and provoked aggression. Among those who received sham stimulation, unprovoked aggression was significantly higher for violent-game players than for nonviolent-game players. Among those who received anodal stimulation, unprovoked aggression did not differ for violent- and nonviolent-game players. Thus, anodal stimulation reduced unprovoked aggression in violent-game players. No significant effects were found for provoked aggression,
\end{abstract}

Electronic supplementary material The online version of this article (doi:10.3758/s13415-016-0490-8) contains supplementary material, which is available to authorized users.

Paolo Riva

paolo.riva1@unimib.it

1 Department of Psychology, University of Milano-Bicocca, Milano, Italy

2 Department of Educational Science - Psychology Unit, University of Genova, Genova, Italy suggesting tit-for-tat responding. This experiment sheds light on one possible neural underpinning of violent-media-related aggression - the rVLPFC, a brain area involved in regulating negative feelings and aggressive impulses.

Keywords Violent video games · Aggression · Self-control · Taylor aggression paradigm (TAP) $\cdot$ Transcranial direct current stimulation (tDCS)

When I was running Atari, violence against humanoid figures was not allowed. We'd let you shoot at a tank ... but we drew the line at shooting at people, with blood splattering everywhere.

- Nolan Bushnell, founder of Atari

Nolan Bushnell, one of the founding fathers of the video game industry, "drew the line" at shooting at people. However, other video game developers have crossed over that line. In many violent video games today, players can kill realistic human-like characters using a wide variety of weapons. Playing violent video games is not just "harmless fun," either. Numerous studies have shown that violent video games can increase aggression (Anderson et al., 2010; Greitemeyer \& Mügge, 2014). A recent report from the American Psychological Association (2015) concluded, "The research demonstrates a consistent relation between violent video game use and increases in aggressive behavior."

However, little is known about the neural mechanisms involved in the link between exposure to violent media and aggression. One possible mechanism is the prefrontal cortex, which regulates executive functions such as self-control (Carnagey, Anderson, \& Bartholow, 2007). In particular, the right ventrolateral prefrontal cortex (rVLPFC) has been implicated in various forms of self-control, including motor control (Chikazoe et al., 2009), risk-taking behavior (Ernst et al., 2002), control over immediate temptations (McClure, Laibson, Loewenstein, \& Cohen, 2004), and emotional 
control (Kim, \& Hamann, 2007; Wager, Davidson, Hughes, Lindquist, \& Ochsner, 2008). Overall, the rVLPFC is wellknown as a fundamental brain region for cognitive and emotional control in general (Berkman, Burklund, \& Lieberman, 2009; Boggio, Rêgo, Marques, \& Costa, 2016; Chester \& DeWall, 2014; Cohen, Berkman, \& Lieberman, 2013; Lieberman et al., 2007), and for response inhibition in particular (Aron \& Poldrack, 2005).

Previous research has shown that stimulating the rVLPFC can reduce the aggression caused by social exclusion (Riva, Romero Lauro, DeWall, Chester, \& Bushman, 2015). However, it is unknown whether stimulating the rVLPFC can reduce aggression caused by other factors, such as exposure to violent media. The present research aims to fill this gap in the literature.

Most researchers define aggression as any behavior intended to harm another person who does not want to be harmed (Baron \& Richardson, 1994; see also Anderson \& Bushman, 2002). Aggression can be either unprovoked or provoked, such as by a perceived threat or an attack. In the present experiment, we measured both unprovoked and provoked aggression. When it comes to aggression, provocation can overpower other factors (Hammock \& Richardson, 1992), including the factors we assessed in this experiment-exposure to violent video games and neuromodulation. Thus, we expected exposure to violent media and anodal transcranial direct current stimulation (tDCS) to have stronger effects on unprovoked than on provoked aggression.

\section{Overview of the present study}

We combined a neuromodulatory technique (i.e., tDCS) with a social psychological manipulation (i.e., exposure to violent video games) to investigate the role of a cortical network in reducing aggression. tDCS allows researchers to identify how changes in the cortical excitability of a particular brain region influence subsequent behavior (Boggio et al., 2016). tDCS is a relatively new and safe noninvasive brain stimulation technique that uses weak electrical currents to induce changes in the cortical excitability of selected brain regions (Nitsche et al., 2008). At a neuronal level, tDCS modulates cortical excitability by shifting the resting membrane potentials in a polaritydependent fashion: Anodal stimulation increases the spontaneous firing rate, whereas cathodal stimulation decreases the spontaneous firing rate. Although these effects are well established at physiological and behavioral levels, they are more controversial at higher levels of cognitive functioning (Jacobson, Koslowsky, \& Lavidor, 2012). Nevertheless, previous evidence has suggested that applying anodal tDCS over the rVLPFC can reduce the aggression caused by social exclusion (Riva, Romero Lauro, DeWall, et al., 2015). In the present experiment, we tested whether applying anodal
tDCS over the rVLPFC can also reduce aggression caused by exposure to violent video games.

In the present study, participants were randomly assigned to play a violent or a nonviolent video game for $20 \mathrm{~min}$. While playing the game, participants were randomly assigned to receive either anodal or sham tDCS over the rVLPFC region of the brain. After gameplay, aggression was measured using the Taylor aggression paradigm (TAP), which measures both unprovoked and provoked aggression. We predicted higher levels of unprovoked aggression among violent-game players than among nonviolent-game players who received sham stimulation. Conversely, we predicted similar levels of unprovoked aggression among violent- and nonviolent-game players who received anodal tDCS applied over the rVLPFC. We based these predictions on the results from a previous study that had targeted the same brain region (Riva, Romero Lauro, DeWall, et al., 2015).

\section{Method}

\section{Participants}

The participants were 80 Italian university students who received $€ 10$ (\$11). One participant was discarded due to a technical error, leaving 79 participants $\left(48 \%\right.$ female; $M_{\mathrm{age}}=$ $21.73, S D=2.38$ ). We used 20 participants per group, on the basis of our previous tDCS research that also used 20 participants per group (e.g., Riva, Romero Lauro, DeWall, \& Bushman, 2012; Riva, Romero Lauro, DeWall, et al., 2015; Riva, Romero Lauro, Vergallito, et al., 2015).

\section{Design}

For the study, we employed a 2 (Videogame Type: nonviolent vs. violent $) \times 2($ tDCS Type: sham vs. anodal $) \times 2($ Aggression Type: unprovoked vs. provoked) mixed factorial design, with the first two factors varying between subjects and the last factor varying within subjects.

\section{Procedure}

First, participants gave informed consent to participate in the study and undergo a manipulation of tDCS. Participants were told that they would take part in a brain stimulation session while playing two different types of computer games. The first computer game constituted our manipulation of exposure to violent video games, whereas the second computer game constituted our measures of unprovoked and provoked aggression.

Participants were randomly assigned to receive anodal tDCS or sham stimulation over the rVLPFC. To stimulate that region, direct current was applied using a constant current 
regulator (DC-STIMULATOR; NeuroConn GmbH, Germany). A pair of saline-soaked sponge electrodes were applied to the participant's scalp. The anode electrode was placed over F6 (MNI coordinates: 58, 30, 8), whereas the cathode electrode was placed over the controlateral supraorbital area. To increase the focality of the stimulation, the anode electrode size was $25 \mathrm{~cm}^{2}$, whereas the cathode electrode size was $50 \mathrm{~cm}^{2}$. The stimulation intensity was set to $1.5 \mathrm{~mA}$. This electrode montage was modeled using COMETS ("computation of electric field due to transcranial current stimulation"; Jung, Kim, \& Im, 2013). As is shown in Fig. 1, considering our montage parameters, the greatest electrical field occurred over the rVLPFC brain region.

All participants were told that they would receive stimulation for $20 \mathrm{~min}$. However, only half actually received a constant current of $1.5 \mathrm{~mA}$ for $20 \mathrm{~min}$. For sham stimulation, the electrodes were placed in the same position, but the stimulator was turned on for only $20 \mathrm{~s}$ (Gandiga, Hummel, \& Cohen, 2006). To mimic the itching sensation of the real stimulation, the current intensity was gradually increased at the beginning of the session ( $8 \mathrm{~s}$ of "ramp up"), and decreased at the end of the session ( $8 \mathrm{~s}$ of "ramp down"). During the remaining time, the stimulation was off but the monitor of the device continued to display the impedance control. Thus, all participants believed they received stimulation for $20 \mathrm{~min}$.

Following the beginning of the anodal tDCS or sham stimulation, participants were randomly assigned to play either a

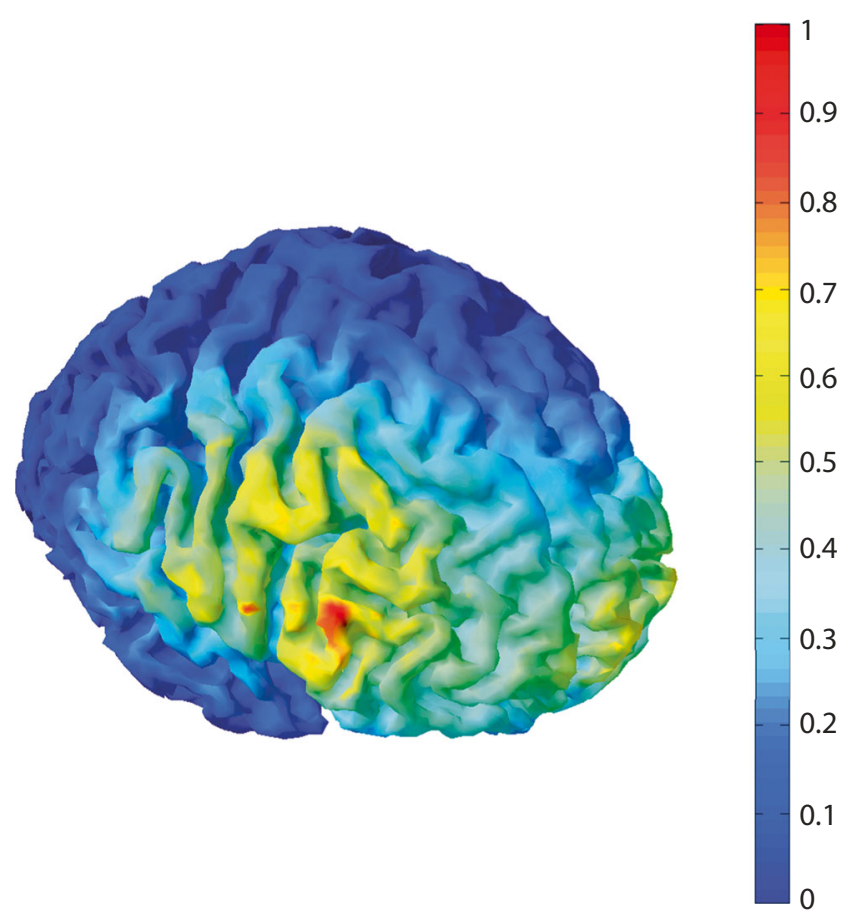

Fig. 1 Computational model of the current flow related to our montage parameters, showing the distribution of the electrical field underneath the target (located over the rVLPFC) and the reference (located over the left supraorbital area) electrodes. The strongest electric field occurs around the cortical area underneath the target electrode violent or a nonviolent video game for $20 \mathrm{~min}$. To increase generalizability (Wells \& Windschitl, 1999), we used two violent video games rated 18+ (Grand Theft Auto III, Grand Theft Auto San Andreas) and two nonviolent video games rated 10+ (C.U.B.E., TRI). This specific set of games had been successfully used in our previous studies (Gabbiadini, Riva, Andrighetto, Volpato, \& Bushman, 2014, 2016).

As manipulation checks, participants reported the title of the video game they played and rated how violent and immoral they thought the game was $(1=$ not at all to $7=$ completely $)$. As a covariate, participants also rated how competitive the game was $(1=$ not at all to $7=$ completely $)$.

Next, participants completed the TAP (Taylor, 1967) with an ostensible opponent of the same gender, which was used to measure both unprovoked and provoked aggression. On this task, participants compete to see who can press a button faster. The winner gets to blast the loser with a loud noise through headphones. The noise was a mixture of noises that many people hate, such as fingernails scratching on chalkboards, dentist drills, blow horns, and sirens. The noise levels ranged from Level $1=$ 60 decibels to Level $10=105$ decibels (about the same level as a fire alarm). A nonaggressive no-noise option (Level 0 ) was also provided. The duration levels ranged from Level $1=0.5 \mathrm{~s}$ to Level $10=5 \mathrm{~s}$. The tasks consisted of a first trial (unprovoked aggression), followed by eight more trials (provoked aggression). Participants always lost the first trial, and received Level 10 intensity and duration noise from their "opponent." Participants lost four of the remaining eight trials (randomly determined), and received random noise intensities and durations on those trials. On the first trial, participants established the noise intensity and duration levels before knowing what noise intensity and duration levels their "opponent" had set. Thus, the first trial is often used to measure unprovoked aggression because it is the only one uncontaminated by tendencies to reciprocate the confederate's level of aggression (e.g., Bushman \& Baumeister, 1998). The remaining trials measure provoked aggression. After the first trial, aggression converged on tit-for-tat (eye-for-an-eye) responding (Axelrod, 1984). The TAP is a well-validated measure of laboratory aggression (Giancola \& Parrott, 2008; Giancola \& Zeichner, 1995), which has been successfully used in several of our previous studies on violent video game effects (e.g., Bushman \& Gibson, 2011; Gabbiadini et al., 2014).

Finally, participants were asked whether they perceived any physical sensation from the electrodes ("yes" or "no"). A full debriefing followed.

\section{Data analytic strategy}

Our main hypothesis was tested using a 2 (Videogame Type: nonviolent vs. violent $) \times 2$ (tDCS Type: sham vs. anodal $) \times 2$ (Aggression Type: unprovoked vs. provoked) analysis of covariance. The between-subjects factors were Type of Video Game Played and Type of tDCS Applied to the Scalp. The 
within-subjects factor was Type of Aggression. The covariates included participant gender, age, and video game competitiveness ratings (see below).

\section{Results}

\section{Preliminary analyses}

Stimulus sampling There were no differences between the two violent games or between the two nonviolent games on unprovoked or provoked aggression levels ( $p s>.16$ ). Thus, the two violent games were combined and the two nonviolent games were combined for the subsequent analyses.

Name of video games All participants correctly indicated the name of the video game they had played.

Violent content of video games Violence ratings were significantly higher for violent video games $(M=5.95, S D=1.30)$ than for nonviolent video games $(M=1.31, S D=0.77), F(1$, $75)=368.75, p<.001, d=4.34$. However, neither a main effect of tDCS, $F(1,75)=0.34, p=.562, d=0.03$, nor an interaction between video games and tDCS, $F(1,75)=1.15, p$ $=.29, \eta_{\mathrm{p}}{ }^{2}=.01$, was found for violence ratings.

Immorality of video games Immorality ratings were significantly higher for violent video games $(M=5.30, S D=1.47)$ than for nonviolent video games $(M=1.33, S D=1.08), F(1$, $75)=203.44, p<.001, d=3.08$. Although there was no main effect of tDCS, $F(1,75)=3.43, p=.068, d=0.20$, a significant interaction was found, $F(1,75)=6.08, p=.016, \eta_{\mathrm{p}}{ }^{2}=$ .08. Specifically, participants receiving anodal tDCS thought the violent games provided higher immorality ratings $(M=$ $5.90, S D=1.17)$ than did participants receiving sham stimulation $(M=4.70, S D=1.52), F(1,75)=9.44, p=.003, d=$ 0.89 . No effect of tDCS occurred for immorality ratings of the nonviolent games, $F(1,75)=0.19, p=.667, d=0.15$.

Competitiveness of video games Competitive ratings were significantly higher for violent video games $(M=4.65, S D=$ $1.58)$ than for nonviolent video games $(M=2.77, S D=1.66)$, $F(1,75)=26.11, p<.001, d=1.16$. However, neither a main effect of tDCS, $F(1,75)=0.54, p=.46, d=0.16$, nor an interaction between video games and tDCS, $F(1,75)=0.12$, $p=.73, \eta_{\mathrm{p}}{ }^{2}=.00$, was found.

Physical sensation from electrodes Similar to past research (Nitsche et al., 2008), we found that few participants (i.e., six of 79 , or $8 \%$ ) reported experiencing physical sensation from the electrodes. Crucially, a Pearson chi-square test showed that self-reported physical sensations did not vary across the four experimental conditions, $\chi^{2}(3)=0.13, p=.54$.
Summary of preliminary analyses In sum, these preliminary analyses showed that participants correctly recalled the names of the games they played, and correctly judged the violent video games to be more violent and immoral than the nonviolent video games. Interestingly, participants who received neuromodulation judged the violent video games to be more immoral than did participants who received sham stimulation. Because participants rated the violent video games to be more competitive than the nonviolent video games, competitive ratings were included as a covariate in the primary analyses. Because some studies have shown gender and age differences in violent video game effects (e.g., Gabbiadini et al., 2016), gender and age were also included as covariates in the primary analyses. The results from the preliminary analyses are given in Table 1 .

\section{Primary analyses}

Because noise intensity and the duration of TAP were significantly correlated for both unprovoked $(r=.61, p<$ $.0001)$ and provoked $(r=.80, p<.0001)$ aggression, they were averaged to form two more reliable indices of aggression (for alternative quantification strategies see supplemental material). None of the covariates were significant [all $F \mathrm{~s}(1,72)<2.08$, all $p \mathrm{~s}>.153$, all $\left.\eta_{\mathrm{p}}{ }^{2} \mathrm{~s}<.02\right]$. Moreover, we found no main effect of type of video game $[F(1,72)=0.93, p=.34, d=0.07]$ or type of aggression $[F(1,72)=0.22, p=.64, d=0.11]$. There was a significant main effect of type of tDCS. As expected, the participants receiving anodal tDCS were less aggressive $(M=5.32, S D$ $=1.96)$ than the participants receiving sham stimulation $(M$ $=4.63, S D=1.31), F(1,72)=4.06, p=.048, d=0.41$.

Most importantly, we observed a significant three-way interaction between type of video game, type of tDCS, and type of aggression, $F(1,72)=6.54, p=.013, \eta_{\mathrm{p}}^{2}=.08^{1}($ see Table 2 for all descriptive statistics). When sham stimulation was applied to the scalp, levels of unprovoked aggression were higher for violent-game players $(M=4.98, S D=2.11)$ than for nonviolent-game players $(M=3.82, S D=2.01), F(1,72)=$ $6.19, p=.015, d=0.56$ (see Fig. 2). However, when anodal tDCS was applied to the scalp, levels of unprovoked aggression did not differ for violent-game players $(M=3.58, S D=$ 1.18) and nonviolent-game players $(M=4.08, S D=1.55)$, $F(1,72)=0.39, p=.54, d=0.36$ (see Fig. 2). Similarly, pairwise comparisons showed that unprovoked aggression was significantly lower following anodal tDCS $(M=3.58$, $S D=1.18)$ than following sham stimulation $(M=4.98, S D$ $=2.11)$ for violent-game players, $F(1,72)=25.69, p=.005, d$ $=0.82$. By contrast, unprovoked aggression did not differ

\footnotetext{
${ }^{1}$ A post-hoc power analysis was conducted using $\mathrm{G}^{*}$ Power, version 3.1 (Faul, Erdfelder, Buchner, \& Lang, 2009), focusing on the key hypothesis regarding the three-way interaction among videogame type, tDCS type, and aggression type manipulation. On the basis of the observed effect size, the results showed a power of .74
} 
Table 1 Demographic variables and manipulation check ratings

\begin{tabular}{lllll}
\hline & \multicolumn{2}{l}{ Violent Video Games } & & \multicolumn{2}{l}{ Nonviolent Video Games } \\
\cline { 2 - 3 } & Sham tDCS & Anodal tDCS & & Sham tDCS \\
\hline Age & $22.90(3.06)$ & $21.25(1.48)$ & $21.21(2.09)$ & $21.55(2.35)$ \\
Females & 7 & 10 & 13 & 8 \\
Males & 13 & 10 & 6 & 12 \\
Violence ratings & $5.75(1.33)$ & $6.15(1.27)$ & $1.37(.83)$ & $1.25(.72)$ \\
Immorality ratings & $4.70(1.53)$ & $5.90(1.17)$ & $1.42(1.39)$ & $2.82(1.89)$ \\
Competitive ratings & $4.85(1.66)$ & $4.45(1.50)$ & & $2.70(1.45)$ \\
\hline
\end{tabular}

between the nonviolent-game players who received sham stimulation $(M=3.82, S D=2.00)$ and the violent-game players who received anodal tDCS stimulation $(M=$ $3.58, S D=1.18), t(37)=0.46, p=.523, d=0.15$. Finally, no significant effects were found for provoked aggression $(p s>.13)$.

\section{Discussion}

Extensive research has shown that exposure to violent video games can increase aggression (e.g., Anderson et al., 2010). In the present research, we replicated this basic finding among participants who received sham stimulation. However, few studies have explored possible ways to reduce aggression levels following exposure to violent video games. Our findings suggest that modulating activity in a brain area implicated in self-control and emotion regulation (i.e., the rVLPFC) can break the causal link between exposure to violent video games and aggression.

Although previous research has shown that the rVLPFC is involved in self-control and emotion regulation (Aron \& Poldrack, 2005; Berkman et al., 2009; Chester \& DeWall, 2014; Chikazoe et al., 2009; Cohen et al., 2013; Ernst et al., 2002; Kim \& Hamann, 2007; Lieberman et al., 2007; McClure et al., 2004; Wager et al., 2008; see also Boggio et al., 2016), only a few studies have used noninvasive brain stimulation techniques to study the role of the prefrontal cortex in setting aggression levels (for a review, see Boggio et al.,
2016). In one study, angered participants who received tDCS to modulate hemispheric asymmetry in frontal cortical activity (anode over left and cathode over right prefrontal cortex) were more aggressive than participants who received sham stimulation (Hortensius, Schutter, \& Harmon-Jones, 2011). In another study, male participants who received anodal tDCS applied over the rDLPFC were less aggressive than male participants who received sham stimulation (Dambacher et al., 2015). More directly, another study showed that stimulation of the rVLPFC can decrease aggression caused by social exclusion (Riva, Romero Lauro, DeWall, et al., 2015). The present study extends this line of research by showing that anodal stimulation over the rVLPFC can eliminate unprovoked aggression caused by exposure to violent video games.

Specifically, our results suggest that anodal tDCS reduces the unprovoked aggression caused by playing violent video games. However, the effect of anodal tDCS holds only for unprovoked, but not for provoked, aggression. We believe that the most straightforward explanation for this lack of a significant tDCS effect on provoked aggression is due to the wellknown finding that provocation often leads to tit-for-tat (eyefor-an-eye) responding (Axelrod, 1984). As we noted above, this is one of the reasons why most of past studies have focused their main analyses on responses provided to the first (i.e., unprovoked aggression) trial (e.g., Bushman, Baumeister, \& Phillips, 2001; Konijn, Nije Bijvank, \& Bushman, 2007). In other words, provocation seems to overpower other factors that increase aggression, such as exposure to violent video games and neuromodulation. However, one

Table 2 Mean ratings of unprovoked and provoked aggression following exposure to violent or nonviolent video games and sham or anodal transcranial direct current stimulation (tDCS)

\begin{tabular}{|c|c|c|c|c|}
\hline & \multicolumn{2}{|c|}{ Violent Video Game } & \multicolumn{2}{|c|}{ Nonviolent Video Game } \\
\hline & Sham tDCS & Anodal tDCS & Sham tDCS & Anodal tDCS \\
\hline Unprovoked aggression & $4.98_{\mathrm{a}}(2.11)$ & $3.58_{\mathrm{b}}(1.18)$ & $3.82_{\mathrm{b}}(2.01)$ & $4.08_{\mathrm{b}}(1.55)$ \\
\hline Provoked aggression & $6.04_{\mathrm{a}}(2.59)$ & $5.61_{\mathrm{a}}(1.65)$ & $6.42_{\mathrm{a}}(1.92)$ & $5.26_{\mathrm{a}}(2.17)$ \\
\hline
\end{tabular}

Higher scores indicate higher levels of aggression; standard deviations are provided in parentheses, and subscripts refer to within-row comparisons. Means having different subscripts are significantly different from each other at $p<.05$. 


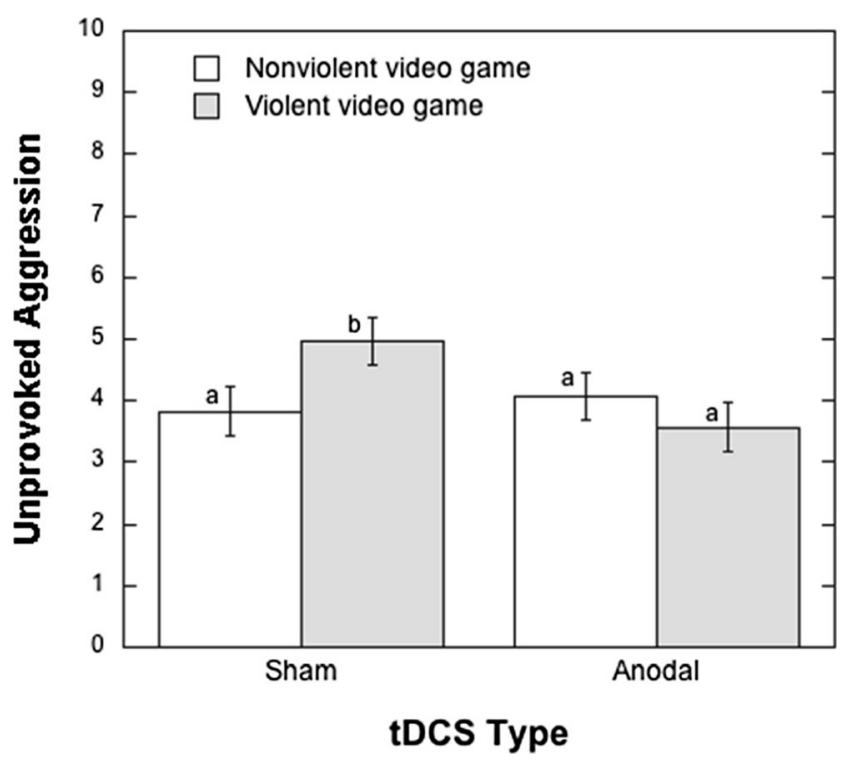

Fig. 2 Effects of violent (vs. nonviolent) video games on unprovoked aggression levels for participants who received sham or anodal tDCS over the rVLPFC. The noise intensity and duration on Trial 1 were averaged to obtain the unprovoked aggression measure. The vertical bars denote one standard error $(S E)$, and means with different letters are significantly different at the .05 significance level

possible dimension that might explain the nonsignificant effects of violent video games and tDCS on provoked aggression is the degree of severity of the provocation feedback. We followed the typical TAP procedure, which implies that participants always lose the first trial and receive the most extreme punishment level available from their "opponent"Level 10 noise intensity and Level 10 duration (scale ranging $0-10$ ). Thus, it is possible that a less severe provocation feedback (e.g., Level 7 on a scale from 0 to 10) could be more easily modulated by situational and neural manipulations, such as exposure to violent media and tDCS.

Our study also suggests that stimulation of the prefrontal cortex can influence the moral evaluation of violent video games. The violent video games used in this study were Grand Theft Auto (GTA) video games. GTA games allow players to engage in several immoral activities (e.g., steal cars, deal drugs, kill pedestrians, and kill prostitutes after paying them for sex to get the money back). Our study found that GTA players who received anodal tDCS judged the games to be more immoral than did GTA players who received sham stimulation. However, this finding was based on a single-item measure of immorality. Thus, future studies should replicate this finding using a more reliable immorality measure.

\section{Limitations and future research}

This study, like all studies, has limitations. One limitation is the low spatial resolution of tDCS. It is possible that other regions of the prefrontal cortex were affected by the stimulation, such as the right dorsolateral prefrontal cortex (DLPFC).
Past tDCS research has shown that modulating the cortical excitability of the right DLPFC affects self-control (Dambacher et al., 2015; Fecteau et al., 2007; Fregni et al., 2008; Goldman et al., 2011). Another region of the right PFC that may have been influenced by the neuromodulation is the right inferior frontal gyrus (rIFG). Indeed, the rVLPFC is part of the rIFG. Patients with unilateral brain lesions over the right PFC have more difficulty controlling their impulses (Aron, Fletcher, Bullmore, Sahakian, \& Robbins, 2003). Both structural and functional magnetic resonance imaging data suggest that the right PFC, and especially the rIFG, may underlie this deficit (for a review, see Aron, Robbins, \& Poldrack, 2014). Anodal tDCS over rIFG has also been successfully used to reduce impulsive behavior (Jacobson, Javitt, \& Lavidor, 2011). Therefore, future research employing other techniques with greater spatial resolution (i.e., transcranial magnetic stimulation) might provide more detailed information about the specific localization of the effect we found.

Another limitation concerns our aggression measures. The fixed order of the two aggression measures, with unprovoked aggression always preceding provoked aggression, may have influenced the pattern of results. However, in the TAP it is not possible to reverse the order of unprovoked and provoked aggression; unprovoked aggression always comes first. Therefore, future work should consider the use of different paradigms to test for methodological artifacts linked with the fixed order of unprovoked and provoked aggression. Moreover, future research should also test the involvement of the rVLPFC in different forms of cognitive and emotional control. Similarly, future research should include trait measures of self-control and trait aggressiveness as possible moderator variables, and state self-control as a possible mediator variable. Finally, future research should also test whether modulating cortical excitability of the rVLPFC can reduce aggression following exposure to other situational factors known to increase aggression (e.g., frustration, crowding, alcohol intoxication, or heat).

\section{Conclusions}

Nolan Bushnell was wise in refusing to create video games in which players can shoot and kill humanoid figures, because research has shown that playing violent video games can increase aggression. The present research suggests that it is possible, however, to break the causal link between exposure to violent video games and aggression by stimulating an area of the brain involved in self-control - the rVLPFC. This research paves the way to the exciting possibilities of reducing aggression more generally by stimulating the self-control centers of the brain, a prospective that might have a great impact, especially for clinical populations. Aggression often starts when self-control stops. 
Author note We thank Alessia Andorno for her help with the data collection.

\section{References}

American Psychological Association. (2015). APA review confirms link between playing violent video games and aggression (Press release). Retrieved from www.apa.org/news/press/releases/2015/08/violentvideo-games.aspx

Anderson, C. A., \& Bushman, B. J. (2002). Human aggression. Annual Review of Psychology, 53, 27-51.

Anderson, C. A., Shibuya, A., Ihori, N., Swing, E. L., Bushman, B. J., Sakamoto, A., \& Saleem, M. (2010). Violent video game effects on aggression, empathy, and prosocial behavior in Eastern and Western countries: A meta-analytic review. Psychological Bulletin, 136, 151-173. doi:10.1037/a0018251

Aron, A. R., Fletcher, P. C., Bullmore, E. T., Sahakian, B. J., \& Robbins, T. W. (2003). Stop-signal inhibition disrupted by damage to right inferior frontal gyrus in humans. Nature Neuroscience, 6, 115-116. doi:10.1038/nn1003

Aron, A. R., \& Poldrack, R. A. (2005). The cognitive neuroscience of response inhibition: Relevance for genetic research in attention-deficit/hyperactivity disorder. Biological Psychiatry, 57, 1285-1292.

Aron, A. R., Robbins, T. W., \& Poldrack, R. A. (2014). Inhibition and the right inferior frontal cortex: One decade on. Trends in Cognitive Sciences, 18, 177-185. doi:10.1016/j.tics.2013.12.003

Axelrod, R. (1984). The evolution of cooperation. New York: Basic Books.

Baron, R. A., \& Richardson, D. R. (1994). Human aggression (2nd ed.). New York: Plenum Press.

Berkman, E. T., Burklund, L., \& Lieberman, M. D. (2009). Inhibitory spillover: Intentional motor inhibition produces incidental limbic inhibition via right inferior frontal cortex. NeuroImage, 47, 705712. doi:10.1016/j.neuroimage.2009.04.084

Boggio, P. S., Rêgo, G. G., Marques, L. M., \& Costa, T. L. (2016). Social psychology and noninvasive electrical stimulation: A promising marriage. European Psychologist, 21, 30-40. doi:10.1027/10169040/a000247

Bushman, B. J., \& Baumeister, R. F. (1998). Threatened egotism, narcissism, self-esteem, and direct and displaced aggression: Does selflove or self-hate lead to violence? Journal of Personality and Social Psychology, 75, 219-229. doi:10.1037/0022-3514.75.1.219

Bushman, B. J., Baumeister, R. F., \& Phillips, C. M. (2001). Do people aggress to improve their mood? Catharsis beliefs, affect regulation opportunity, and aggressive responding. Journal of Personality and Social Psychology, 81, 17-32.

Bushman, B. J., \& Gibson, B. (2011). Violent video games cause an increase in aggression long after the game has been turned off. Social Psychological and Personality Science, 2, 29-32.

Carnagey, N. L., Anderson, C. A., \& Bartholow, B. D. (2007). Media violence and social neuroscience: New questions and new opportunities. Current Directions in Psychological Science, 16, 178-182. doi:10.1111/j.1467-8721.2007.00499.x

Chester, D. S., \& DeWall, C. N. (2014). Prefrontal recruitment during social rejection predicts greater subsequent self-regulatory imbalance and impairment: Neural and longitudinal evidence. NeuroImage, 101, 485-493.

Chikazoe, J., Jimura, K., Asari, T., Yamashita, K. I., Morimoto, H., Hirose, S., \& Konishi, S. (2009). Functional dissociation in right inferior frontal cortex during performance of go/no-go task. Cerebral Cortex, 19, 146-152. doi:10.1093/cercor/bhn065

Cohen, J. R., Berkman, E. T., \& Lieberman, M. D. (2013). Intentional and incidental self-control in ventrolateral PFC. In D. T. Stuss \& R. T.
Knight (Eds.), Principles of frontal lobe function (2nd ed., pp. 417440). Oxford: Oxford University Press.

Dambacher, F., Schuhmann, T., Lobbestael, J., Arntz, A., Brugman, S., \& Sack, A. T. (2015). Reducing proactive aggression through noninvasive brain stimulation. Social Cognitive and Affective Neuroscience, 10, 1303-1309. doi:10.1093/scan/nsv018

Ernst, M., Bolla, K., Mouratidis, M., Contoreggi, C., Matochik, J. A., Kurian, V., \& London, E. D. (2002). Decision-making in a risktaking task: A PET study. Neuropsychopharmacology, 26, 682-691.

Faul, F., Erdfelder, E., Buchner, A., \& Lang, A.-G. (2009). Statistical power analyses using $\mathrm{G}^{*}$ Power 3.1: Tests for correlation and regression analyses. Behavior Research Methods, 41, 1149-1160. doi:10.3758/BRM.41.4.1149

Fecteau, S., Knoch, D., Fregni, F., Sultani, N., Boggio, P., \& PascualLeone, A. (2007). Diminishing risk-taking behavior by modulating activity in the prefrontal cortex: A direct current stimulation study. Journal of Neuroscience, 27, 12500-12505. doi:10.1523 /JNEUROSCI.3283-07.2007

Fregni, F., Orsati, F., Pedrosa, W., Fecteau, S., Tome, F. A., Nitsche, M. A., \& Boggio, P. S. (2008). Transcranial direct current stimulation of the prefrontal cortex modulates the desire for specific foods. Appetite, 51, 34-41.

Gabbiadini, A., Riva, P., Andrighetto, L., Volpato, C., \& Bushman, B. J. (2014). Moral disengagement moderates the effect of violent video games on self-control, cheating and aggression. Social Psychological and Personality Science, 5, 451-458.

Gabbiadini, A., Riva, P., Andrighetto, L., Volpato, C., \& Bushman, B. J. (2016). Acting like a tough guy: Violent-sexist video games, identification with game characters, masculine beliefs, \& empathy for female violence victims. PLOS ONE, 11, e0152121. doi:10.1371 /journal.pone.0152121

Gandiga, P. C., Hummel, F. C., \& Cohen, L. G. (2006). Transcranial DC stimulation (tDCS): A tool for double-blind sham-controlled clinical studies in brain stimulation. Clinical Neurophysiology, 117, 845850.

Giancola, P. R., \& Parrott, D. J. (2008). Further evidence for the validity of the Taylor aggression paradigm. Aggressive Behavior, 34, 214 229.

Giancola, P. R., \& Zeichner, A. (1995). Construct validity of a competitive reaction-time aggression paradigm. Aggressive Behavior, 21, 199-204.

Goldman, R. L., Borckardt, J. J., Frohman, H. A., O’Neil, P. M., Madan, A., Campbell, L. K., \& George, M. S. (2011). Prefrontal cortex transcranial direct current stimulation (tDCS) temporarily reduces food cravings and increases the self-reported ability to resist food in adults with frequent food craving. Appetite, 56, 741-746.

Greitemeyer, T., \& Mügge, D. O. (2014). Video games do affect social outcomes: A meta-analytic review of the effects of violent and prosocial video game play. Personality and Social Psychology Bulletin, 40, 578-589. doi:10.1177/0146167213520459

Hammock, G. S., \& Richardson, D. R. (1992). Predictors of aggressive behavior. Aggressive Behavior, 18, 219-229.

Hortensius, R., Schutter, D. J., \& Harmon-Jones, E. (2011). When anger leads to aggression: Induction of relative left frontal cortical activity with transcranial direct current stimulation increases the anger-aggression relationship. Social Cognitive and Affective Neuroscience, 7, 342-347.

Jacobson, L., Javitt, D. C., \& Lavidor, M. (2011). Activation of inhibition: Diminishing impulsive behavior by direct current stimulation over the inferior frontal gyrus. Journal of Cognitive Neuroscience, 23, 3380-3387.

Jacobson, L., Koslowsky, M., \& Lavidor, M. (2012). tDCS polarity effects in motor and cognitive domains: A meta-analytical review. Experimental Brain Research, 216, 1-10. doi:10.1007/s00221-011-2891-9

Jung, Y. J., Kim, J. H., \& Im, C. H. (2013). COMETS: A MATLAB toolbox for simulating local electric fields generated by transcranial 
direct current stimulation (tDCS). Biomedical Engineering Letters, 3, 39-46.

Kim, S. H., \& Hamann, S. (2007). Neural correlates of positive and negative emotion regulation. Journal of Cognitive Neuroscience, 19, 776-798.

Konijn, E. A., Nije Bijvank, M., \& Bushman, B. J. (2007). I wish I were a warrior: The role of wishful identification in the effects of violent video games on aggression in adolescent boys. Developmental Psychology, 43, 1038-1044. doi:10.1037/0012-1649.43.4.1038

Lieberman, M. D., Eisenberger, N. I., Crockett, M. J., Tom, S. M., Pfeifer, J. H., \& Way, B. M. (2007). Putting feelings into words affect labeling disrupts amygdala activity in response to affective stimuli. Psychological Science, 18, 421-428. doi:10.1111 /j.1467-9280.2007.01916.x

McClure, S. M., Laibson, D. I., Loewenstein, G., \& Cohen, J. D. (2004). Separate neural systems value immediate and delayed monetary rewards. Science, 306, 503-507. doi:10.1126/science.1100907

Nitsche, M. A., Cohen, L. G., Wassermann, E. M., Priori, A., Lang, N., Antal, A., \& Paulus, W. (2008). Transcranial direct current stimulation: State of the art 2008. Brain Stimulation, 1, 206-223.

Riva, P., Romero Lauro, L. J., DeWall, C. N., Chester, D. S., \& Bushman, B. J. (2015). Reducing aggressive responses to social exclusion using transcranial direct current stimulation. Social Cognitive and Affective Neuroscience, 10, 352-356. doi:10.1093/scan/nsu053

Riva, P., Romero Lauro, L. J., DeWall, C. N., \& Bushman, B. J. (2012). Buffer the pain away: Stimulating the rVLPFC reduces pain following social exclusion. Psychological Science, 23, 1473-1475.

Riva, P., Romero Lauro, L. J., Vergallito, A., DeWall, C. N., Chester, D. S., \& Bushman, B. J. (2015). Electrified emotions: Modulatory effects of transcranial direct stimulation on negative emotional reactions to social exclusion. Social Neuroscience, 10, 46-54. doi:10.1080/17470919.2014.946621

Taylor, S. P. (1967). Aggressive behavior and physiological arousal as a function of provocation and the tendency to inhibit aggression. Journal of Personality, 35, 297-310.

Wager, T. D., Davidson, M. L., Hughes, B. L., Lindquist, M. A., \& Ochsner, K. N. (2008). Prefrontal-subcortical pathways mediating successful emotion regulation. Neuron, 59, 1037-1050. doi:10.1016 /j.neuron.2008.09.006

Wells, G. L., \& Windschitl, P. D. (1999). Stimulus sampling and social psychological experimentation. Personality and Social Psychology Bulletin, 25, 1115-1125. 